University of Pennsylvania Carey Law School

Penn Law: Legal Scholarship Repository

Faculty Scholarship at Penn Law

$1-12-2009$

\title{
Social Facts, Constitutional Interpretation, and the Rule of Recognition
}

Matthew D. Adler

University of Pennsylvania Carey Law School

Follow this and additional works at: https://scholarship.law.upenn.edu/faculty_scholarship

Part of the Constitutional Law Commons, Jurisprudence Commons, and the Public Law and Legal Theory Commons

\section{Repository Citation}

Adler, Matthew D., "Social Facts, Constitutional Interpretation, and the Rule of Recognition" (2009). Faculty Scholarship at Penn Law. 247.

https://scholarship.law.upenn.edu/faculty_scholarship/247

This Article is brought to you for free and open access by Penn Law: Legal Scholarship Repository. It has been accepted for inclusion in Faculty Scholarship at Penn Law by an authorized administrator of Penn Law: Legal Scholarship Repository. For more information, please contact PennlawIR@law.upenn.edu. 


\title{
SOCIAL FACTS, CONSTITUTIONAL INTERPRETATION, AND THE RULE OF RECOGNITION
}

\author{
Matthew D. Adler ${ }^{1}$ \\ Forthcoming, Matthew D. Adler and Kenneth Einar Himma, eds., The Rule of \\ Recognition and the U.S. Constitution (Oxford U. Press 2009)
}

\section{Introduction}

How do participants in the U.S. legal system argue about constitutional interpretation? Constitutional scholars and leading jurists have long been preoccupied with elaborating different possible interpretive methods, such as an original-intent approach, an original-meaning approach, John Hart Ely's representation-reinforcement method, Cass Sunstein's “minimalism,” the "structure and relationship” approach defended by Charles Black, and so forth. ${ }^{2}$ I want to shift the discussion a level up. What is the structure of argumentation about the different possible approaches?

For short, I will call an argument or statement in favor of some approach to interpreting the U.S. Constitution a "CI" (constitutional interpretation) argument or statement, and the total body of such statements "CI-discourse.” Someone who participates in this discourse is a "CI-participant."

Oddly, constitutional scholars have given little attention to the semantics of CIdiscourse. There are scores of books and hundreds of law review articles contributing to CI-discourse, but very little scholarship that analyzes the discourse itself. ${ }^{3}$

Several related puzzles about CI-discourse are worth reflecting upon. One is differentiating between legal and non-legal arguments for interpretive methods. It is certainly possible to advance a non-legal argument for some interpretive method -- for example, to argue that some method has a favorable moral status, while leaving open the question of its legal status. However, as we shall see, CI-participants often claim, explicitly or implicitly, that some interpretive method has a favorable legal status -- by

\footnotetext{
${ }^{1}$ Leon Meltzer Professor, University of Pennsylvania Law School. Many thanks to Mitch Berman, Michael Dorf, Kent Greenawalt, Alon Harel, Ken Himma, Matt Lister, Stephen Perry, and Kevin Toh, for their written comments; to the other authors in this book, for helpful discussions at a University of Pennsylvania Law School conference where initial chapter drafts were discussed; and to participants in a legal theory workshop at the University of Texas Law School, where I presented an initial draft.

${ }^{2}$ Prominent scholarly and judicial discussions of constitutional interpretation are analyzed in Part III. For references to other scholarship on constitutional interpretation, see CONSTITUTIONAL THEORY: ARGUMENTS AND PERSPECTIVES (Michael Gerhardt et al. eds., 3d ed. 2007).

${ }^{3}$ The few extant discussions of CI-discourse include Richard Fallon, How To Choose a Constitutional Theory, 87 CAL. L. REv. 535 (1999), with commentaries by Michael Dorf and David Strauss, see 87 CAL. L. REV. at 581, 593; and Philip Bobbitt's work, see CONSTITUTIONAL FATE (1982); CONSTITUTIONAL INTERPRETATION (1991).
} 
which I mean either the minimally favorable status of being legally permitted, or some more strongly favorable status, such as being legally required, or supported by a legal presumption, or supported by the balance of legal considerations.

But what exactly is the structure of a legal -- as opposed to non-legal -- argument for an interpretive method? What is the feature of an interpretive method that CIparticipants see as conferring a favorable legal status upon that method? And are CIparticipants correct on this score? What is the feature of an interpretive method that actually does make it legally permitted, required, or otherwise favored?

Another puzzle concerns the role of social facts in CI-arguments. As we shall see, CI-arguments often point to social facts as part of the grounds for the favorable legal status of some interpretive method. By social facts, I mean facts about the behaviors, utterances, or mental states of some group of individuals in the U.S., either past or present. It turns out that three kinds of social facts figure repeatedly in CI-arguments: facts about the Framers' intent, facts about judicial precedent (that is, facts about judicial behavior, utterances or mental states), and facts about our constitutional culture or tradition.

But does the nexus between an interpretive method and certain social facts indeed function to establish that the interpretive method is legally permitted, required, or otherwise favored? If so, how do social facts play this role? Does the nexus between an interpretive method and certain social facts indeed function to establish that judges or other actors have a genuine reason to employ some interpretive method? If so, how do social facts play this role?

As an exemplar of CI-argument, consider Thomas Grey’s famous article, "Do We Have an Unwritten Constitution?" ${ }^{4}$ Grey argues for nontextualism: for "[c]onstitutional adjudication going beyond the norms implicit in text and original history." ${ }^{5}$ He is quite explicit in distinguishing between the question whether nontextualism is normatively attractive in some non-legal sense (what he calls "the question of practical wisdom", $)$, and the question of its legal status. "Even if this mode of judicial review [nontextualism] produces good results in the eyes of some beholders, and even if it is not intrinsically unjudicial, there remains the question whether in our Constitution we have actually granted this large power to our judges." 7 And Grey makes clear his intention to argue that nontextualism is legally favored. He writes:

In resolving this issue of legal authority, there seems to me only one plausible method of inquiry. We must apply the conventional and accepted categories of legal argument - original understanding, judicial precedent, subsequent history, and internal consistency -- and see if they support judicial review that goes beyond [textualism].

${ }^{4} 27$ StAn. L. REV. 703 (1975).

${ }^{5} \mathrm{Id}$. at 714 .

${ }^{6} \mathrm{Id}$.

${ }^{7}$ Id. at 715 . 
I believe that when these tests are applied, constitutional adjudication of the sort objected to by Mr. Justice Black and the other proponents of the pure [textualist] model will be seen to be a lawful and legitimate feature of our system of judicial review. ${ }^{8}$

Grey’s appeal to “original understanding,” “judicial precedent,” and "subsequent history” is -- I suggest -- quite remarkable. Understand that Grey is not proposing “original understanding," “judicial precedent,” or "subsequent history” as first-order interpretive methods that judges should employ in reading the text of the Constitution. Constitutional scholars and jurists make such proposals all the time, and no one would be surprised by them. Rather, he is proposing "original understanding," "judicial precedent," and "subsequent history" as second-order criteria for choosing among interpretive methods.

And, in the remainder of the article, Grey adduces facts about precedent, original understanding, and U.S. constitutional culture and tradition to argue in favor of nontextualism. He labors at length to show the inconsistency between textualism and Supreme Court case law in areas such as substantive due process, the application of the Bill of Rights to the states, and the application of equal protection norms to the federal government. He concludes: “[A]n extraordinarily radical purge of established constitutional doctrine would be required if we candidly and consistently applied the [textualist] model. Surely that makes out at least a prima face practical case against the model."9

Grey claims that the Framers were nontextualists:

For the generation that framed the Constitution, the concept of a "higher law,” protecting “natural rights,” and taking precedence over ordinary positive law as a matter of political obligation, was widely shared and deeply felt. An essential element of American constitutionalism was the reduction to written form -- and hence to positive law -- of some of the principles of natural rights. But at the same time, it was generally recognized that written constitutions could not completely codify the higher law. Thus in the framing of the original American constitutions it was widely accepted that there remained unwritten but still binding principles of higher law. ${ }^{10}$

Finally, he points to an ongoing tradition of invoking fundamental, unwritten rights, starting with the Framers, continuing with the anti-slavery constitutionalists, then the Lochner-era proponents of liberty of contract, and ending with contemporary commitment to the rights of privacy, voting, travel, and other unwritten rights. "[This] is

\footnotetext{
${ }^{8} \mathrm{Id}$.

${ }^{9}$ Id. at 713 .

${ }^{10} \mathrm{Id}$. at $715-16$.
} 
the modern offspring, in a direct and traceable line of legitimate descent, of the natural rights tradition that is so deeply embedded in our constitutional origins."11

Can we "make sense" of the appearance of social facts about precedent, Framers' intent, and U.S. constitutional culture and tradition in Grey's article and the other places in CI-discourse where these social facts appear? To put the question more precisely: can we develop a framework for CI-discourse that (1) describes, with reasonable accuracy, the sorts of arguments that Grey and other CI-participants are actually making; and that (2) vindicates characteristic features of CI-discourse, namely the CI-participant's assertion or presupposition that some interpretive method is legally favored; that social facts contribute to the legally favored status of this method; and that judges and other actors have a genuine reason to employ the legally favored method?

A full analysis of these questions would require a comprehensive survey of jurisprudentially plausible accounts of law and legal discourse, seeing how well each one functions to describe and vindicate CI-discourse. Such an analysis is beyond the scope of this chapter. Rather, I begin at the beginning: with Hart's rule-of-recognition account. ${ }^{12}$ This account is the foundation for all contemporary work on the nature of law in the Anglo-American philosophical tradition, both by positivists, who build upon Hart's account, and by Dworkinians, who proceed in reaction to it. ${ }^{13}$

The rule-of-recognition model includes a semantics for legal statements. According to Hart, legal systems always include committed participants, who take the "internal point of view" towards a rule stating ultimate criteria of legal validity (the rule of recognition). In that state of mind, committed participants make "internal” legal statements. Notably, as we shall see, internal legal statements assert or presuppose a certain kind of social fact: namely, the fact that present officials in the society accept the rule of recognition.

The rule-of-recognition account of the semantics of legal statements -- for short, "RoR" semantics -- might seem to be a promising framework for CI-discourse in the United States. Reference to social facts is both a characteristic feature of CI-discourse, and a pivotal element of RoR semantics. For Hart, it is the social fact of official acceptance of the rule of recognition, together with general efficacy of the legal duties flowing from the RoR, that gives rise to certain kind of social reality: a legal system. The difference between a genuine and a spurious legal position (right, duty, power, etc.) is just that the genuine position has the right nexus, direct or indirect, to the rule of recognition. And the difference between a legal statement, and some other type of

\footnotetext{
${ }^{11}$ Id. at 717.

${ }^{12}$ See H.L.A. HART, THE CONCEPT OF LAW (2d ed. 1994) [hereinafter “COL”].

${ }^{13}$ Ronald Dworkin's jurisprudential views are most comprehensively stated in LAW's EMPIRE (1986). The reader unfamiliar with contemporary jurisprudential debates might begin by reading JULES L. COLEMAN, The Practice of Principle: In Defence of a Pragmatist ApProach to Legal Theory (2001); and the chapters in HART's POSTSCRIPT: ESSAYS ON THE POSTSCRIPT TO THE CONCEPT OF LAW (Jules Coleman ed., 2001).
} 
normative statement, is (in part) that a legal statement makes reference to the fact of official acceptance of the rule of recognition. ${ }^{14}$

However, as I will show in this chapter, RoR semantics does not accurately describe CI-discourse, nor does it help vindicate various characteristic aspects of CIdiscourse. One key problem, which should already be evident, is that the kinds of social facts that figure in CI-discourse are different from those that figure in RoR semantics: not facts about a present official consensus, but rather facts about precedent, culture/tradition, and Framers' intent. Another problem, which is not apparent from the Grey article but will emerge below, is the heterogeneity of appeals to social facts in CI-discourse. Some CI-participants, such as Grey, appeal to precedent, Framers' intent, and culture/tradition. But some CI-participants appeal only to one or two of these kinds of facts, and some to none. More strikingly, some CI-participants explicitly disclaim reliance upon precedent; some explicitly disclaim reliance upon Framers’ intent; and some explicitly disclaim reliance upon culture/tradition.

Part I of this chapter discusses the various dimensions for evaluating a candidate semantics for some normative discourse, such as CI-discourse. Part II explicates RoR semantics. Part III reviews a sample of CI-discourse and discusses how social facts figure therein. Part IV analyzes whether RoR semantics describes or vindicates CIdiscourse reasonably well, and reaches a negative conclusion.

Part V looks beyond the rule-of-recognition model, in an initial and exploratory way. The fact that RoR semantics fails to describe and vindicate CI-discourse does not necessarily indicate a flaw in RoR semantics and, more generally, Hart's account of law. Reaching that conclusion, based on the analysis in this chapter, would be premature. We should be open to the possibility that CI-discourse is a misguided body of argument -- at least to the extent that participants argue for the favorable legal (rather than merely moral) status of controversial interpretive methods, and for the role of certain social facts in buttressing this status. CI-participants may just be incorrect to think that an interpretive method can be legally favored, absent a current official consensus supporting the method; and that facts about precedent, Framers' intent, or culture/tradition provide legal support for interpretive methods, absent a current official consensus that such facts play this role. In short, we should be open to an "error theory" of CI-discourse -- a theory which says that some of the assertions or presuppositions characteristic of CI-discourse are, in fact, systematically false.

To be clear, this chapter does not embrace an "error theory” of CI-discourse. Part V merely suggests, in a preliminary manner, why various alternatives to RoR semantics -- such as successor positivist frameworks, Dworkinian semantics, and grouprelative semantics -- may also have difficulty in both describing and vindicating CIdiscourse.

\section{Semantic Frameworks}

\footnotetext{
${ }^{14}$ See Part II.
} 
CI-discourse is normative. CI-participants recommend interpretive methods. This chapter will consider whether RoR semantics provides a satisfactory semantics for CI-discourse. At the threshold, then, we need to think about the criteria for evaluating a candidate semantics for some normative discourse.

Scholarship in metaethics on the semantics of moral statements is helpful in this regard. ${ }^{15}$ One proposed semantics for moral discourse is cognitivist. According to a cognitivist semantics, moral statements assert the speaker's belief in some proposition. Cognitivists note that the surface grammar of moral statements is propositional -speakers ascribe the property of "rightness" or "goodness" to actions or outcomes. Cognitivists also note features of moral discourse most readily explained by a propositional semantics, for example: (1) the fact that speakers sometimes disagree with each other, which is most readily explained as a conflict of beliefs, namely one speaker believing some moral proposition which another disbelieves; and (2) the fact that speakers make deductive inferences from moral premises to moral conclusions, in accordance with the norms of propositional logic, again most readily explained if moral statements express beliefs in propositions.

Noncognitivists deny that a moral statement is an assertion of the speaker's belief in some proposition. Their position is that moral statements express some non-belief state, such as an emotion, a commitment, or a plan. They ask cognitivists to explain the link between moral statements and motivation. Normally, when a speaker makes a sincere moral statement, she is motivated to behave consistently with that statement. But beliefs, without more, don't motivate.

Noncognitivists also ask cognitivists whether moral statements -- if they indeed express propositions -- can possibly be true? What are the properties of "rightness" and "goodness"? Some cognitivists respond to this challenge by arguing that moral properties are nonnatural properties. Others claim that moral properties are natural properties. Still others adopt an "error theory" of moral discourse. John Mackie, the most famous expositor of this approach, combines a cognitivist moral semantics with an ontology that denies the existence of moral properties. Mackie takes the position that moral statements assert propositions which, however, are never true. ${ }^{16}$

Drawing from this scholarship on moral semantics, I will take the following approach to thinking about CI-statements. A “semantics” offers a model or framework for some target discourse, such as some normative discourse. This model characterizes the target discourse as consisting in one or more kinds of speech-acts. The model can be evaluated along different dimensions. I will mention three (there may be others). One dimension is descriptive. The model can be better or worse in describing the statements that the participants in the target discourse are actually making. Another dimension is

\footnotetext{
${ }^{15}$ For an overview, see AleXANDER Miller, An InTROduction to Contemporary MetAethics (2003).

${ }^{16}$ See JoHn MACKIE, ETHics: InVENTING Right AND WrOng (1977); MiLLER, INTRODUCTION TO CONTEMPORARY METAETHICS, at 111-27.
} 
explanatory. The model can be better or worse in explaining why the participants are making these statements.

Another dimension, for lack of a better word, is the dimension of vindication. Roughly speaking, what I mean by this is whether speech-acts that conform to the model tend to be made by speakers who are logical, rational, and accurate in their view of the world. One aspect of vindication has to do with the truth of those factual statements that the model licenses. Insofar as the semantics licenses statements where speakers express their beliefs, are those statements generally true or untrue?

I don't have a grand theory about which dimensions "matter" more, in evaluating a candidate semantics for some discourse. It seems to me that different scholars will focus on different dimensions, depending on their interests. For example, a sociologist developing a semantics for legal discourse may not care at all about the dimension of vindication; while a legal scholar who is both trying to get a handle on the semantics of legal discourse, and is participating herself in legal discourse, will presumably care about the dimension of vindication. Presumably she doesn't want to develop a framework for her own arguments that will lead her to make false claims.

A Dworkinian or Davidsonian ${ }^{17}$ about these matters might insist that a candidate semantics is a failure unless it vindicates the target discourse sufficiently. I don't take that position. The sociologist might deny the existence of moral properties (on the grounds that such properties have no role in our best scientific theories of the physical and social worlds), but construe moral statements as expressing beliefs in moral properties (on the grounds that such beliefs best explain the deductive inferences that participants in moral discourse make) -- ending up with an error theory of moral discourse. Error theories of other areas of discourse remain live options in the relevant scholarly literatures. ${ }^{18}$ For example, it is surely the case that a scholar can study and theorize about religious discourse without believing in God herself.

I focus in this chapter on the problem of describing and vindicating CI-discourse, given that my own interests are jurisprudential (to understand when some interpretive method is genuinely legally favored) and normative (to understand when judges and other actors genuinely have a reason of some kind to employ an interpretive method). I emphatically do not mean to suggest that any scholar studying CI-discourse must have this combination of aims.

\section{Hart's Semantics of Legal Statements}

Hart's Concept of Law sets forth a model of a legal system, involving the familiar notions of an ultimate criterion of legal validity, the rule of recognition, towards which

\footnotetext{
${ }^{17}$ Donald Davidson, that is. CITE.

${ }^{18}$ On error theories, see Brian Leiter, Explaining Theoretical Disagreement (Oct. 1, 2008; unpublished paper, on file with author).
} 
officials take the "internal point of view"; derivative legal rules validated by the rule of recognition; and general efficacy of the valid conduct-regulating rules. ${ }^{19}$

One part of Hart's model is a semantics for legal statements. He distinguishes between "internal statements" and "external statements," the former being made by those who take the internal point towards the rule of recognition. ${ }^{20}$

Participants in CI-discourse accept, or seem to accept, the normative force of the U.S. Constitution; they seem to be doing something like taking the internal point of view towards it, or towards a rule of recognition validating it. It is therefore Hart's model of internal legal statements, rather than his model of external legal statements, which seems a more promising candidate to describe and vindicate CI-discourse, and which shall be my focus in this chapter.

Recent scholarship by Kevin Toh has dissected The Concept of Law and Hart's other writings in great detail and has argued persuasively that Hart's semantics for internal legal statements were noncognitivist. ${ }^{21}$ Stephen Perry and Scott Shapiro reach the same conclusion. ${ }^{22}$ Toh offers the following gloss on Hart: "In making an internal legal statement, according to [Hart], a speaker (i) displays his acceptance of a particular norm as the rule of recognition of his legal system; and (ii) presupposes that this rule of recognition is generally accepted by the officials of his community." 23 According to this framework, what the speaker making an internal legal statement explicitly expresses is not some belief -- for example, a belief that the rule of recognition is binding, or legitimate, or anything like that -- but rather a non-belief state of accepting or being committed to the rule of recognition.

So we have a substantial problem, right off the bat, in using Hart's model of internal legal statements as the semantics for CI-discourse. All things considered, it seems that noncognitivism does a pretty poor job of describing and vindicating moral discourse. And these deficits would presumably carry over to a noncognitivist semantics for other kinds of normative discourse, such as legal discourse. For example, legal speakers make deductive inferences about which legal positions (rights, duties, etc.) exist. Such inferences can be correct if “assertions” of legal positions are genuine assertions, expressing beliefs in propositions, but are very difficult to see as correct otherwise. Indeed, Stephen Perry has argued at length that the best semantics for legal discourse is cognitivist. $^{24}$

However, it is not too difficult to reformulate Hart's semantics along cognitivist lines. This cognitivist reformulation is meant as a friendly amendment -- one intended to

\footnotetext{
${ }^{19}$ See COL at 78-117.

${ }^{20}$ See id. at 102-03.

${ }^{21}$ See Kevin Toh, Hart's Expressivism and his Benthamite Project, 11 LEgAL THEORY 75 (2005).

${ }^{22}$ See Stephen Perry, Hart on Social Rules and the Foundations of Law: Liberating the Internal Point of View, 75 Fordham L. Rev. 1143 (2006); Perry [this volume]; Scott J. Shapiro, What is the Internal Point of View?, 75 FORDHAM L. REV. 1157 (2006).

${ }^{23}$ Toh, Hart's Expressivism, at 112-13.

${ }^{24}$ See Perry, Hart on Social Rules; Perry [this volume]
} 
bolster the ability of RoR semantics to describe and vindicate U.S. legal discourse, in particular CI-discourse.

What exactly should the reformulation be? One key aspect of Hart's model of a legal system, obviously, is the way in which it rests upon a social practice. According to Hart, officials in any legal system instantiate a special kind of social practice vis a vis the rule of recognition: they accept it, comply with it, criticize officials who deviate from it, and accept this criticism as legitimate. For short, I will call this practice official "acceptance" of the rule of recognition.

The social practice foundational to a legal system, according to Hart, is a contemporaneous official practice. The Concept of Law makes crystal clear that the rule of recognition is the norm stating ultimate validity criteria that is accepted by officials, and that the rule of recognition need not be accepted by citizens. Nor, it seems, is the rule of recognition merely accepted by judges; rather, officials in general, including legislators and other non-judicial officials as well as judges, necessarily accept it. ${ }^{25}$ As for the rule's temporal features: Hart's discussion of the emergence of new legal systems suggests that the rule of recognition for a legal system at some time $\mathrm{T}$ is the ultimate criterion of legal validity accepted by officials at $\mathrm{T}^{26}$

Internal legal statements, according to Hart, make reference to the fact that officials accept the rule of recognition. Internal statements do not explicitly state this fact, but neither do they ignore it. Rather, Hart says, an internal legal statement presupposes the social fact of official acceptance of the rule of recognition. ${ }^{27}$

A second key aspect of a legal system, according to Hart, is the foundationalist character of legal reasoning. There is an ultimate criterion of legal validity, the rule of recognition, which "can neither be valid nor invalid," 28 and subordinate legal rules, which are validated by derivation from the rule of recognition. And, although Hart is not fully explicit about this point, the Concept of Law seems to say this: A speaker who makes an internal statement asserting a legal duty or some other legal position pursuant to a subordinate rule presupposes that this subordinate rule can be derived from the rule of recognition. $^{29}$

I therefore suggest the following cognitivist reformulation of Hart's semantics, which retains the central idea that an internal legal statement makes reference to a special kind of social fact, and incorporates Hart's foundationalist picture of legal reasoning. It

\footnotetext{
${ }^{25}$ On the official-centric cast of the rule-of-recognition, see Matthew D. Adler, Popular Constitutionalism and the Rule of Recognition: Whose Practices Ground U.S. Law?, 100 NORTHWESTERN U. L. REV. 719, 729-37 (2006).

${ }^{26}$ See COL at 117-23.This is consistent with Hart's sociological aims. The fact that officials accept some rule at $\mathrm{T}$, as opposed to the fact that they accepted some rule at a previous time, is more explanatory with respect to official behavior at $\mathrm{T}$.

${ }^{27}$ On the presuppositions of an internal statement see COL at 104, 108-09; Toh, Hart's Expressivism, at 88, $112-13$

${ }^{28} \mathrm{COL}$ at 109 . On the rule of recognition as the ultimate legal criterion, see generally id. at 105-08.

${ }^{29}$ See id. at 102-03, 108.
} 
also preserves the normative character of internal legal statements -- the critical difference from external statements. I will henceforth drop the term "internal” and refer to internal legal statements as simply "legal statements."

\section{RoR Semantics for Legal Statements}

A legal statement:

(1) Asserts the existence of some legal position (a duty, right, liberty, etc) [Legal character];

(2) Asserts or presupposes that the legal position has normative force, providing genuine reasons for the holder of the position and/or those who hold connected positions [Normative character];

(3) Asserts or presupposes that this legal position can be derived from an ultimate criterion of legal validity, the rule of recognition; [Foundationalism]

(4)Asserts or presupposes that the rule of recognition is generally accepted by present officials [Social fact: present official acceptance]

(5) Asserts or presupposes that the duties derivable from the rule of recognition are generally complied with by citizens as well as officials [Social fact: general efficacy]

(6) Asserts or presupposes that the combination of (3), (4) and (5) is part of the grounds for (1) and (2) [Nexus between social facts and legal and normative character]

The reader might wonder why someone who has engaged in normative deliberation under favorable epistemic conditions and then makes an internal legal statement would ever assert or presuppose (6). How could a rational, well-informed speaker ever believe that the mere social facts of official acceptance of the rule of recognition and general efficacy could furnish genuine normative grounds for anyone to comply with the rule of recognition or with legal positions derivable from it?

I should note that Hart's own interests were not to vindicate the normative cast of legal discourse ${ }^{30}$; but, in any event, there are plausible answers to the question just raised. As various post-Hartian positivists have noted, the social facts of official practice might solve a coordination problem, or generate reliance interests. ${ }^{31}$ Or, official practice might have epistemic authority, furnishing evidence of what some individual has genuine normative reason to do.

Hart scholars might also object that RoR semantics is not Hart's semantics. Why go through the exercise of applying it to CI-discourse? The answer is that Hart's actual semantics, just in virtue of being noncognitivist, will fail to function as a good model (given my interests) of CI-discourse. The question I want to ask is this: if we drop that feature of the semantics, and use a cognitivist semantics which in other respects is as

\footnotetext{
${ }^{30}$ See Part IV.

${ }^{31}$ See, e.g., Coleman, Practice OF PRINCIPLE, at 87-100.
} 
close as possible to Hart's, can we do a decent job describing and vindicating CIdiscourse?

\section{Sample of CI-Discourse}

This Part examines a sample of twenty-four instances of CI-argument -- by legal scholars or judges -- to see how social facts figure therein. A CI-argument defends or criticizes an "interpretive method," by which I mean some view either about the sources of constitutional law (i.e., whether the 1787 text as amended is the exclusive source or, if not, what the additional sources are) or about the approach that judges and other actors should use to interpret those sources.

I selected the sample as follows. I limited myself to post-New Deal examples. I also limited myself to books, articles and speeches, which provide the fullest discussion of interpretive methods, rather than judicial opinions, which sometimes do defend a method but are invariably briefer.

I began by choosing the most famous and influential instances of CI-argument. I then supplemented this initial list with additional texts so that my sample included at least one defense of each of the interpretive methods that has substantial current support. Finally, so as to be sure that the sample was not overly weighted towards scholars rather than judges, I added all the examples I could find of post-New Deal Supreme Court justices providing extended defenses of some interpretive method in books, articles, or speeches.

The sample is:

-- Bruce Ackerman, We the People: Foundations, vol. 1 (1991)

-- Alexander M. Bickel, The Least Dangerous Branch: The Supreme Court at the Bar of Politics (2d ed. 1986)

-- Charles Black, Structure and Relationship in Constitutional Law (1969)

-- Hugo LaFayette Black, A Constitutional Faith (1969)

-- Robert H. Bork, The Tempting of America: The Political Seduction of the Law (1990)

-- William J. Brennan, Jr., “The Constitution of the United States: Contemporary Ratification” (1985)

-- Stephen Breyer, Active Liberty: Interpreting Our Democratic Constitution (2005)

-- Ronald Dworkin, Law’s Empire (1986)

--John Hart Ely, Democracy and Distrust: A Theory of Judicial Review (1980)

-- Felix Frankfurter, "Some Observations on the Nature of the Judicial Process of Supreme Court Litigation” (1954)

-- Ruth Bader Ginsburg, "Speaking in a Judicial Voice” (1992)

--Thomas Grey, “Do We Have an Unwritten Constitution?” (1975)

-- Learned Hand, The Bill of Rights (1958) 
--Richard H. Fallon, Jr. “A Constructivist Coherence Theory of Constitutional Interpretation” (1987)

-- Robert H. Jackson, The Supreme Court in the American System of Government (1955)

--Michael J. Perry, The Constitution, the Courts, and Human Rights: An Inquiry into the Legitimacy of Constitutional Policymaking by the Judiciary (1982)

--Richard A. Posner, "Against Constitutional Theory” (1998)

--William H. Rehnquist, “The Notion of a Living Constitution” (1976)

--Antonin Scalia, “Originalism: The Lesser Evil” (1989)

--John Paul Stevens, “The Bill of Rights: A Century of Progress” (1992)

--David A. Strauss, "Common Law Constitutional Interpretation"

-- Cass R. Sunstein, One Case at a Time: Judicial Minimalism on the Supreme Court (1999)

--Herbert Wechsler, “Toward Neutral Principles of Constitutional Law” (1959)

--Keith E. Whittington, Constitutional Interpretation: Textual Meaning, Original Intent, and Judicial Review (1999) ${ }^{32}$

The sample certainly cannot be thought to be representative of CI-discourse in general (which includes discourse by private citizens and non-elite officials). At most, the sample is representative of CI-discourse by legal elites. The desire to find full discussions of interpretive methods, for comparison in detail to RoR semantics, pushed me in this direction. I have focused on the most influential CI-discourse by scholars and jurists, in the hopes that an instance of CI-discourse is influential just because it exemplifies what scholars and jurists see as an appropriate CI-argument.

So the sample is just a first stab at understanding the state of CI-discourse. If the findings prove of interest, more research may be warranted.

In this Part, I first confirm that most CI-participants in my sample do indeed typically seek to defend some interpretive method as having a favorable legal status.

Then, I describe the social facts that the authors in the sample explicitly rely upon, or explicitly disclaim reliance upon.

To be sure, the RoR template, as I have reconstructed it, provides that a speaker making a legal statement may either explicitly assert or presuppose (without explicit assertion) the social fact of present official acceptance of the rule of recognition. It would be very difficult to compactly summarize the social facts that the authors presuppose without explicitly asserting, and I do not attempt to do that here. The next Part discusses whether the RoR template accurately describes CI-argument, and that Part

\footnotetext{
32 Justice Stevens' essay was published as a chapter in THE BILL OF RightS IN THE MODERN STATE, at 13 (Geoffrey R. Stone et al. eds, 1992). The remaining items on this list other than books were published as articles in the following journals. Brennan: 19 U.C. DAVIS L. REV. 2 (1985). Frankfurter: 98 PROC. AM. PhIL. SoC. 233. Ginsburg: 67 N.Y.U. L. ReV. 1185. Grey, 27 StAN. L. ReV. 703. Fallon: 100 HARV. L. Rev. 1189. Posner: 73 N.Y.U. L. Rev. 1. Rehnquist: 54 Tex. L. Rev. 693. Scalia: 57 U. Cincinnati L. REV. 849. Strauss: 63 U. CHI. L. REV. 877. Wechsler: 73 HARV. L. REV. 1.
} 
is sensitive to the possibility that authors are presupposing without asserting relevant social facts.

What emerges from the sample is the following. First, many authors explicitly rely on social facts in arguing for interpretive methods: in particular, social facts within the three categories of judicial precedent, Framers' intent, or what I shall term "culture/tradition" facts. Further, although I will not belabor the point in the description below of particular CI-arguments, a reading of these sources shows that authors who rely on social facts to support interpretive methods explicitly or implicitly do so in order to support the favored legal status of the interpretive method (not just to assert that the interpretive method is favored in some non-legal sense).

I do not find a single instance in which an author explicitly relies upon present official practice to support an interpretive method. Some authors appeal to present or past-and-present citizen practices, which include the practices of present officials (who are a subset of citizens) but also include the practices of non-official citizens.

Finally, the pattern of appeal to social facts in the sample of CI-discourse is heterogeneous. Some authors explicitly rely upon social facts within all three categories. Others rely upon some but not all categories. And, most strikingly, for each category there are some authors who disclaim reliance upon social facts within the category.

\section{Legal Arguments}

Characterizing CI-argument as legal or non-legal is, concededly, a subtle matter.

To begin, it may well be the case that a legal argument draws on moral considerations. Indeed, Dworkin (although not Hart) takes the position that a legal argument is just a special variety of moral argument. So the test for distinguishing between legal and non-legal CI discourse is not whether the argumentation draws on moral considerations, but whether its aim is to establish that an interpretive method has a favorable legal status, or merely a favorable status in some non-legal sense, one that does not in turn entail a favorable legal status.

Further, CI-participants sometimes make both legal and non-legal arguments. To give one example: Justice Rehnquist argues that the "living Constitution" approach to constitutional interpretation, i.e., nontextualism, "misconceives the nature of the Constitution, which was designed to enable the popularly elected branches of government, not the judicial branch, to keep the country abreast of the times"33 and that it also "ignores the Supreme Court's disastrous experiences when in the past it embraced contemporary, fashionable notions of what a living Constitution should contain." ${ }^{34}$ The first quoted passage seems to make a legal argument for textualism. Presumably Rehnquist is not appealing to the Constitution's nature and how it was designed (Framers' intent) to show merely that textualism has a favored non-legal status. But the

\footnotetext{
${ }^{33}$ Rehnquist at 699.

${ }^{34}$ Id.
} 
second quoted passage could well be a non-legal argument, seeking to show that textualism has better consequences than nontextualism.

However, virtually none of the CI-participants in my sample advance solely nonlegal arguments. Virtually all argue, inter alia, that one or another interpretive method has a favorable legal status. Sometimes, this is explicit, as in Grey's claim that nontextualism is a "lawful and legitimate feature of our system of judicial review"35; or Herbert Wechsler's claim that courts, qua "courts of law," have "the duty when a case is properly before them” to adjudicate constitutional claims using neutral principles. ${ }^{36}$

Often, the legal status of CI-argument is implicit, but clear. For example, Justice Scalia argues for originalism along the following lines:

The principle theoretical defect of nonoriginalism ... is its incompatibility with the very principle that legitimizes judicial review of constitutionality. ... Central to [Marbury's argument for judicial review] is the perception that the Constitution, though it has an effect superior to other laws, is in its nature the sort of 'law' that is the business of the courts -- an enactment that has a fixed meaning ascertainable through the usual devices familiar to those learned in the law. If the Constitution were not that sort of a 'law,' but a novel invitation to apply current societal values, what reason would there be to believe that the invitation was addressed to the courts rather than to the legislature? ${ }^{37}$

It is very hard to see Scalia, here, as merely arguing that originalism has good moral credentials without necessarily having good legal credentials. Clearly, Scalia's intention is to show that originalism is legally favored (indeed, legally required).

Robert Bork, Keith Whittington, and Justice Black argue, along lines similar to Scalia, that textualism or originalism is entailed by the status of the written Constitution as higher law. Although none of these authors say explicitly that judges have a legal duty to employ textualism or originalism, that seems clearly implicit. ${ }^{38}$

As we shall in a moment, a number of scholars (such as Ackerman, Dworkin, Ely, Fallon, Strauss, and Perry) defend interpretive methods with reference to our culture and traditions. Although it is certainly possible to make a non-legal argument based on culture and tradition, the particular manner in which these scholars draw on culture/tradition makes clear that their aim is to show that some method is legally favored. ${ }^{39}$ For example, Strauss writes: "Perhaps common law constitutionalism is not

\footnotetext{
${ }^{35}$ Grey at 715 .

${ }^{36}$ Wechsler at 19.

${ }^{37}$ Scalia at 854.

${ }^{38}$ See Bork at 139-60; Whittington at 15-16 (clarifying that his aim is to provide two arguments for originalism, one based on the existence of a written Constitution; and a second, based on popular sovereignty," that "does not depend on the prior acceptance of the current constitutional system"); id. at 47109 (providing first argument); Hugo Black at 7-10.

${ }^{39}$ See infra pp. ___ Dworkin defends his favored approach to constitutional interpretation by engaging in constructive interpretation -- which, for him, is just the hallmark of a legal argument. Fallon also says
} 
the best we could do if we were writing on a blank slate. But unless our current practices are to be rejected wholesale, the common law model is .... the best way to understand what we are doing." 40 To argue that some interpretive method is the best understanding of our legal practices, even though it might not be the best method to set up ab initio, is surely just to argue that the method is legally favored (indeed, not just permitted, but legally required, or at least favored in a stronger sense than permissibility).

Without belaboring the point, I suggest that all the other authors in the sample can be seen as arguing for the favorable legal status of an interpretive method, with only a few possible exceptions. ${ }^{41}$ One is Judge Posner, who may be read as skeptical about the very possibility of judicial duties apart from the promotion of good consequences. Another, perhaps, is Sunstein, who argues that "minimalism" promotes deliberative democracy, ${ }^{42}$ but also states that "the American constitutional system aspires ... to a

explicitly that he is engaging in constructive interpretation. Strauss seems to be engaged in an approach close to constructive interpretation and, in any event, it is clear (as the quotation immediately below shows) that Strauss intends to provide a legal argument for common law constitutionalism. The extent to which Ackerman, Ely, and Perry are inspired by Dworkin is less clear, but in any event Ackerman and Ely (as the quotations at pp. _ _ will show) clearly do not intend to provide straight moral arguments for their favored methods. As for Perry, he makes clear that he is concerned with the "legitimacy" rather than "soundness" of noninterpretive review. See Perry at 4-5. And, by "legitimacy," Perry pretty clear seems to mean legal rather than moral legitimacy. He writes that if "interpretive review ... is authorized by the constitutional text ... the practice is legitimate. Indeed, if mandated and not merely authorized by the text, the practice is obligatory.” Id. at 12.

${ }^{40}$ Strauss at 888.

${ }^{41}$ Justice Breyer argues at length that his “active liberty' approach to Constitutional interpretation is supported by Framers' intent, see Breyer, at 21-34. He also argues that it "helps make sense of our Constitution's structure.” Id. at 6. Alexander Bickel says explicitly that the grounding of an interpretive method in precedent provides support for the method. See Bickel at 48. And his book describes, at length, how courts have followed his favored method (bringing "principle" to bear in constitutional adjudication, while also exercising the passive virtues).

It would be unusual to draw upon these sort of considerations - the structure of the Constitution, Farmers' intent, judicial precedent -- to make a non-legal argument for some conclusion about what judges or other actors ought to do.

Justice Stevens draws on Framers' intent to support courts' use of a common-law process to expand the scope of constitutionally protected liberties. Further, he explains that this reliance on Framers' intent is meant to show that judicial expansion of liberty has not merely been "progress," but that such progress has been achieved "by legitimate means." See Stevens at 34-36.

Justice Ginsburg draws on Framers' intent to argue for an approach to constitutional interpretation whereby judges achieve progress via a dialogue with legislatures, see Ginsburg at 1185-86, 1208; and also embeds this approach in a theory of the good judge, see, e.g., id. at 1209.

Justice Frankfurter argues that an interpretive approach to the Due Process Clause which allows its meaning to evolve over time flows from the nature of law. See Frankfurter at 234-35. He also appeals to Framers' intent: The Constitution "was designed for a developing nation." Id at 235-36 (internal quotation omitted).

Judge Hand famously argues that "[f]or myself it would be most irksome to be ruled by a bevy of Platonic Guardians” (see Hand at 73), which might seem like simple moral disapproval of expansive judicial review; but his basic argument for limited review proceeds from the text of the Constitution, rather than moral considerations. "I have been ... trying to say what is the measure of judicial intervention that can be thought to be implicit, though unexpressed, in the Constitution.” Id. at 67 .

Justice Brennan argues that judges should make substantive value judgments, and that doing so is required "[t]o remain faithful to the content of the Constitution." Brennan at 6.

${ }^{42}$ See, e.g., Sunstein at xiv. 
system of deliberative democracy."43 The latter statement suggests that Sunstein's intention is to defend the legal status of minimalism by appealing to a value, deliberative democracy, which is not only a moral value but also has legal force in our system. Similarly, Justice Jackson argues that an activist approach to constitutional adjudication is undemocratic and "promising of [no] permanent good to the country," 44 but also argues that for judges to depart from a restrained approach would be a "usurpation" of judges' limited powers under the Constitution. ${ }^{45}$ Finally, Charles Black explains that he admires "structure and relationship" reasoning because:

[W]here a fairly available method of legal reasoning, by its very nature, leads directly to the discussion of practical rightness [as does structure-and-relationship reasoning], that method should be used wherever possible. It is the best wisdom of every system of law to seek and to cleave unto such intellectual modes. ${ }^{46}$

Black's position seems to be that structure-and-relationship reasoning is at least legally permitted in virtue of being morally advisable.

In short, although some parsing of the texts is certainly required, there is little doubt that a very substantial fraction of CI-discourse aims to show the favorable legal status of some interpretive method.

\section{Explicit Reliance upon Precedent}

Supreme Court case law is often discussed in CI-discourse. But I would not infer, from the sheer fact that a CI-participant discusses precedent, that she views an interpretive method's grounding in precedent as support for the method. She may be discussing precedent just to illustrate the method.

But a substantial number of CI-participants go beyond merely discussing precedent, and explicitly take the position that the grounding of an interpretive method in precedent is support for the method. Thomas Grey does so, as we have seen. Similarly, Alexander Bickel in The Least Dangerous Branch, criticizing Learned Hand's defense of extremely limited judicial review, writes: "There is a great deal to be said ... for a theory that is able to accommodate ... more of what the Court has done in fact than Judge Hand was able to accept." "47 And much of the Least Dangerous Branch attempts to show that the Supreme Court has acted consistently with Bickel's favored approach to constitutional adjudication, namely a dual approach whereby courts both apply “principle,” and employ various “passive virtues” so as to respect democratic values. ${ }^{48}$

\footnotetext{
${ }^{43}$ Id. at 24.

44 Jackson at 58, 61.

${ }^{45} \mathrm{Id}$. at 61 . See also id. at 79.

${ }^{46}$ Charles Black at 23.

${ }^{47}$ Bickel at 48.

${ }^{48}$ See id. at 69-72, 199-200, for a general statement of the dual approach. Bickel's discussion of the case law is at $111-272$.
} 
Other CI-participants make culture/tradition arguments for their favored methods, and quite explicitly include judicial decisions as one element of culture/tradition. Strauss argues for an incrementalist, "common law" approach to constitutional interpretation that countenances departures from the text and from Framers' intent. His overall strategy is two-pronged: to show that "it is the common law approach, not the approach that connects law to an authoritative text, or an authoritative decision by the Framers ... that best explains, and best justifies, American constitutional law today."49 Strauss therefore describes various aspects of our constitutional "practice" which are inconsistent with textualism or a Framers' intent methodology. This "practice” includes, as one component, judicial precedent.

There are a number of specific aspects of our practice of constitutional interpretation that are well-settled, and that lie at the core of how constitutional law operates in our society, but that are difficult to justify under any theoretical approach [other than Strauss' favored approach]. These puzzles concern not just how the courts interpret the Constitution but how the Constitution is received in the society as a whole. ${ }^{50}$

Richard Fallon, similarly, looks to the practices of "judges, lawyers, and other constitutional interpreters” to defend his “constructivist coherence” approach to constitutional interpretation. $^{51}$

Bruce Ackerman in We the People defends a "dualist” view of constitutional change and interpretation, which assigns judges a "preservationist” role: judicial interpretation of the original text plus formal as well as informal amendments. The overall strategy of We the People is to show that all the actors in the U.S. system -judges, officials, and citizens -- have acted consistently with “dualism” since $1787 .{ }^{52}$ As part of this overall strategy, Ackerman makes substantial efforts to show that judges have more or less successfully executed their "preservationist" role. ${ }^{53}$

\section{Explicit Reliance on Framers’ Intent}

Many authors rely on Framers’ intent in arguing for an interpretive method. This includes authors whose favored method is textualist or originalist. For example, William

\footnotetext{
${ }^{49}$ Strauss at 879 . See also id. at 888 (explaining that his aim is to identify the interpretive method that best describes and justifies our practices).

${ }^{50} \mathrm{Id}$. at 880 .

${ }^{51}$ See Fallon at 1239; see also id. at 1248 (explaining that "judicial opinions" as well as "briefs [and] scholarly articles” in fact engage in constructivist coherence reasoning).

${ }^{52}$ See infra pp.

${ }^{53}$ See, e.g., Ackerman at 60-61(stating that he aims to show that judges have fulfilled a preservationist role). Among other things, Ackerman's arresting claim that the Constitution was informally amended during the New Deal, expanding national power and removing constraints on economic regulation, essentially relies on the content of post-1937 judicial doctrine. The claim would be completely implausible if the Supreme Court's Commerce Clause and substantive due process case law had not changed so radically around 1937.
} 
Rehnquist argues against the notion of a "living Constitution" on multiple grounds, including the fact that:

[I]t misconceives the nature of the Constitution, which was designed to enable the popularly elected branches of government, not the judicial branch, to keep the country abreast of the times. . .

It seems to me that it is almost impossible, after reading the record of the Founding Fathers' debates in Philadelphia, to conclude that they intended the Constitution itself to suggest answers to the manifold problems that they knew would confront succeeding generations. ${ }^{54}$

Similarly, Robert Bork, in a chapter section entitled "the original understanding of original understanding,” argues that originalism “corresponds to the original understanding of the place of courts in our republican form of government. .... The structure of government the Founders of this nation intended most certainly did not give courts a political role." 55 Justice Black's defense of textualism also appeals to Framers' intent. $^{56}$ Bruce Ackerman, an idiosyncratic originalist, relies upon the Federalist Papers' commitment to "dualism" as part of his broader culture/tradition argument for “dualism." 57

However, many CI-participants who defend some non-textualist or non-originalist interpretive method also rely on Framers' intent to defend their favored method -- either a as a separate basis for justifying an interpretive method, or as one component of a broader culture/tradition argument. Thomas Grey, strikingly, falls into the first category. So do Justices Ginsburg, Stevens, Breyer, and Frankfurter. Ginsburg argues that the Supreme Court can "reinforce or signal a green light for a social change" through a "temperate brand of decisionmaking," as exemplified by the gender discrimination cases (as contrasted with Roe v. Wade. $)^{58}$ And in partial support of this interpretive method, she writes: "What I hope to convey about courts .... is in line with the founders'-- Madison's

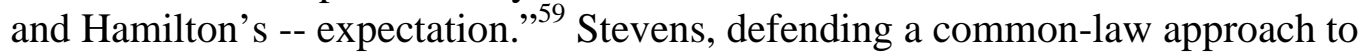
constitutional interpretation, writes:

I firmly believe that the Framers of the Constitution expected and intended the vast open spaces in our charter of government to be filled not only by legislative enactment but also by the common-law process of step-by-step adjudication that was largely responsible for the development of the law at the time this nation was conceived. ${ }^{60}$

\footnotetext{
${ }^{54}$ Rehnquist at 699.

${ }^{55}$ Bork at 154-55.

${ }^{56}$ See Hugo Black at 10, 19.

57 Ackerman at 165-99.

${ }^{58}$ Ginsburg at 1208 .

${ }^{59} \mathrm{Id}$. at $1185-86$.

${ }^{60}$ Stevens at 35-36.
} 
Breyer, in the course of defending an interpretive method centered around the concept of "active liberty," spends 14 pages arguing that the Framers valued "active liberty" and designed the Constitution to promote it. ${ }^{61}$ Frankfurter defends a view of due process which permits its content to evolve over time by noting, inter alia, that the Constitution was designed "for a developing nation."62

John Ely is a nonoriginalist who invokes Framers' intent as part of a broader appeal to culture/tradition. Ely rejects originalism or traditionalism as interpretive methods, arguing instead for a non-originalist methodology centered on the goal of representation-reinforcement. But, in arguing for representation-reinforcement, Ely appeals to our tradition of valuing democracy - starting at the beginning, with the Framing.

We have as a society from the beginning, and now almost instinctively, accepted the notion that a representative democracy must be our form of government. The very process of adopting the Constitution was designed to be ... more democratic than any that had preceded it. ${ }^{63}$

Ely goes on to support this assertion by citing passages from the Federalist papers. ${ }^{64}$

\section{Explicit Reliance Upon Culture/Tradition}

Philip Bobbitt, in his classic study of judicial styles of constitutional reasoning, includes a separate category of "ethical” argument: "Ethical constitutional arguments do not claim that a particular solution is right or wrong in any sense larger than that the solution comports with the sort of people we are .... "65 A good example is the Supreme Court's reliance on tradition in defining family and parental rights as a matter of substantive due process. ${ }^{66}$

"Ethical” arguments, in Bobbitt's sense, also play a substantial role at a different level of constitutional discourse -- the level of CI-discourse. I will call these "culture/tradition" arguments, and will define them inclusively: as arguments that appeal to the practices and understandings of a larger group of U.S. actors than judges or Framers. The temporal scope of these arguments is heterogeneous. Some give priority to present practices, ${ }^{67}$ others make reference to both present and past practices without

\footnotetext{
${ }^{61}$ Breyer at 21-34.

${ }^{62}$ Frankfurter at 235-36 (internal quotation omitted).

63 Ely at 5.

${ }^{64}$ See id. at 5-6.

65 BobBitT, CONSTITUtional FATE, at 94-95.

${ }^{66} \mathrm{CITE}$

${ }^{67}$ I place in this category Dworkin (for reasons discussed in Adler, Popular Constitutionalism, at 737-45) and Strauss. Strauss at various points speaks of interpreting our "current practices" or our practices “today.” See Strauss at 879, 887, 888. For Strauss (as I read him), prior judicial decisions are relevant to constitutional interpretation, as a matter of our practices, because it is our present practices to look to these decisions.
} 
priority for the present, and I will include both types under the heading of culture/tradition arguments.

A substantial number of CI-participants make culture/tradition arguments (including scholars who would reject a traditionalist or conventionalist approach to interpreting the due process clause or other parts of the Constitution). Dworkin, obviously, does so: he argues that his favored method of constitutional interpretation, a nonoriginalism that protects substantive rights, ${ }^{68}$ emerges from a "constructive interpretation” of our preinterpreted constitutional practices. As I read Dworkin, these preinterpreted practices are the shared present understandings, among all citizens, about the content of the law. ${ }^{69}$

Richard Fallon, explicitly relying on Dworkin (with some minor disagreements), defends his "constructivist coherence" approach to constitutional interpretation as a "theory of our practice of constitutional interpretation [which is] neither purely descriptive nor purely normative."70 David Strauss, as already noted, defends a commonlaw approach to constitutional decisionmaking by arguing (inter alia) that it best fits "how the Constitution is received in the society as a whole."71 Strauss tries to distance himself from Dworkin, but the substance of his strategy for CI-argument, like Fallon's, seems pretty close to Dworkinian constructive interpretation. ${ }^{72}$

Other CI-participants who rely upon culture/tradition arguments include Ely, Perry, and Ackerman, as well as Grey (already discussed). Ely’s Democracy and Distrust is oriented around the countermajoritarian difficulty. "[R]ule in accord with the consent of a majority of those governed is the core of the American governmental system."73 The book begins with a lengthy statement of the countermajoritarian difficulty; criticizes extant interpretive methods on various grounds, including their countermajoritarian cast; and defends representation-reinforcement on the grounds that it is workable in the hands of judges, consistent with the text of the Constitution, and consistent with majoritarian democracy. Notably, as Michael Dorf discusses in an incisive treatment of Democracy and Distrust, Ely does not present a straight moral argument for majoritarian democracy. ${ }^{74}$ Ely notes in a footnote "I have suggested that the appeal of democracy can best be understood in terms of its connections with the philosophical tradition of utilitarianism,"75 but does not in fact present a utilitarian case for democracy. ${ }^{76}$ Instead, he argues that majoritarian democracy is rooted in our traditions, both the Framers' original design and later practice, concluding that: "Our constitutional development ...

${ }^{68}$ See Dworkin at 355-99.

69 See Adler, Popular Constitutionalism, at 737-46.

${ }^{70}$ Fallon at 1233. On Fallon's intention to engage in constructive interpretation, see generally id. at 1231-

37. For his disagreement with Dworkin, see id. at 1233 n.206, 1235 n. 213.

${ }^{71}$ Strauss at 880 . See also id. at 888.

72 See Strauss at 888 n. 35.

73 Ely at 7.

${ }^{74}$ Michael C. Dorf, The Coherentism of Democracy and Distrust, 114 YALE L.J. 1237 (2005).

${ }^{75}$ Ely at 187 n. 14.

${ }^{76}$ Instead, Ely goes on in the footnote to say that "nothing in the ensuing analysis depends on this claim." Id. 
[has] substantially strengthened the original commitment to control by a majority of the governed. Neither has there existed among theorists or among Americans generally any serious challenge to the general notion of majoritarian control.”77

Michael Perry defends what he calls “noninterpretive,” i.e., nonoriginalist review in the area of human rights by invoking what he calls the "religious" element of American culture/tradition -- "a basic, irreducible feature of the American people's understanding of themselves."78 This "religious self-understanding has generally involved a commitment ... to the notion of moral evolution.”, "And "[n]oninterpretive review ... has enabled us, as a people, to keep faith with . . . our religious understanding of ourselves as a people committed to struggle incessantly to see beyond ... the imperfections of whatever happens at the moment to be the established moral conventions." ${ }^{80}$ In short, Perry roots noninterpretive review in a deep American tradition of looking beyond current moral conventions. ${ }^{81}$

Ackerman's We the People very clearly refrains from making a straight moral argument for "dualism." Instead, the thrust of the book is to show that American political practice, from the Framing through the present, has more or less conformed to the dualist template. He stresses that the book is "anti-utopian":

We have been searching for the spirit of this Constitution, not some better one. The ultimate question is not whether this Constitution meets the standards of our highest moral ideals ... but whether it is good enough to warrant respectful and conscientious support. $^{82}$

The aim of We the People is "to capture the spirit of the existing historical enterprise"83-to describe the "development [of dualism] through three constitutional regimes, by reflecting upon its source in the revolutionary tradition, and by exploring the way it continues to control normal and constitutional politics in America." ${ }^{84}$ Ackerman specifically identifies at least one aspect of dualism that, he believes, is truly a feature of it -- given our traditions -- but is morally flawed: the fact that dualism does not allow constitutional rights to be entrenched. ${ }^{85}$

\section{Explicit Reliance on Officials?}

\footnotetext{
${ }^{77}$ Id. at 7. See also id. at 54, 59 (arguing that interpretive approaches that allow judges to make substantive judgments are inconsistent with the views of "our society" about the existence of objective moral principles and about the role of judges).

${ }^{78}$ Perry at 97.

${ }^{79} \mathrm{Id}$. at 99.

${ }^{80} \mathrm{Id}$. at 101.

${ }^{81}$ Admittedly, Perry waffles somewhat on the question whether he sees the nexus between the method of noninterpretive review and our tradition of moral evolution as affirmative support for the method. See id. at 99, 101-02, 106, 125.

${ }^{82}$ Ackerman at 296.

${ }^{83}$ Id. at 321.

${ }^{84} I d$. at 296. For other places where Ackerman suggests his enterprise is to reconstruct our practices, see, e.g., id. at 3-6, 22-24.

${ }^{85}$ See id. at 13-15, 319-22.
} 
Do participants in CI-discourse ground arguments for an interpretive methodology in the practices of officials?

I find no instance where a CI-participant cites the current practices of the totality of officials. For that matter, I find no instance where a CI-participant cites the past practices, or the past-and-present practices, of the totality of officials.

CI-participants do occasionally cite facts about individual officials to support an interpretive method. For example, Lincoln's constitutional views and activities are discussed approvingly by several CI-participants, ${ }^{86}$ and Ackerman discusses a number of other Presidents. ${ }^{87}$ Very occasionally, a CI-participant will explicitly discuss the practices of a subset of officials (for example, Ackerman's discussion of the role of the Republican Party in spearheading a constitutional moment during the Reconstruction period). ${ }^{88}$

What about appeals to culture/tradition? The thrust of a culture/tradition argument is to appeal to widely shared practices. The large group of individuals whose behaviors and mental states constitute these practices presumably includes all or many present officials. But the CI-participants in my sample who make culture/tradition arguments pretty clearly intend to refer to the behaviors and mental states of non-official citizens as well.

Dworkin, on my reading, is a “deep popular constitutionalist”: it is the shared present understandings of citizens generally, not just officials, which are the data for constructive interpretation. ${ }^{89}$ Strauss argues that common-law constitutionalism best fits "how the Constitution is received in society as a whole." 90 Fallon defends his constructivist-coherence approach by engaging in an interpretation of the practices of lawyers, including both officials and non-official lawyers. ${ }^{91}$ Grey, in noting the grounding of non-textualism in post-Framing history, points to the natural rights views of the anti-slavery movement (a paradigmatic citizen constitutional movement). ${ }^{92}$ Ely describes the acceptance of majoritarian democracy among the American citizenry, not just American officials: "Neither has there existed among theorists or among American generally any serious challenge to the general notion of majoritarian control."93 Michael Perry stresses the "religious" self-understanding of the "American people," not just American officials. ${ }^{94}$ Ackerman points to the popular mobilization during the 1860 s and

\footnotetext{
${ }^{86}$ See Stevens at 23; Bickel at 65-69.

${ }^{87}$ See, e.g., Ackerman at 67-86.

${ }^{88}$ See id at $45-46$.

${ }^{89}$ See Adler, Popular Constitutionalism, at 737-45.

${ }^{90}$ Strauss at 880 .

${ }^{91}$ On Fallon's focus on lawyers, see Fallon at 1193 (discussing opinions, briefs, and scholarly argument as elements of our legal culture); 1248 (same); 1239 (citing facts about "judges, lawyers, and other

constitutional interpreters” as evidence for his approach).

92 See Grey at 716.

93 Ely at 7.

${ }^{94}$ See Perry at 97, 98, 101, 106.
} 
1930s as examples of "higher lawmaking" leading to constitutional amendments. The fact that citizens, in these instances, conformed to the "dualist" template is an important part of his argument that our traditions are dualist. ${ }^{95}$

\section{$\underline{\text { Not relying upon, or disclaiming reliance upon, social facts }}$}

Some authors explicit rely on all three categories of social facts I have outlined here, while some rely only on one or two, and others on none. ${ }^{96}$ Most strikingly, for each category of social fact, there are authors who disclaim reliance upon it.

A number of authors stress the inconsistency of their favored interpretive methodology with precedent. These authors go beyond simply indicating that some prior case law is inconsistent with their preferred method. Rather, these CI-participants show that large amounts of exiting case law are inconsistent with some interpretive method, which they nonetheless view as legally favored. Such a discussion implicitly seems to indicate the CI-participant's belief that the absence of a link between precedent and a method does not undermine its favorable legal status. ${ }^{97}$

For example, Justice Black criticizes much Due Process and First Amendment case law as inconsistent with textualism. ${ }^{98}$ Robert Bork lambastes the Warren, Burger and Rehnquist courts as all "display[ing] a strong affinity for legislating policy in the name of the Constitution." 99

Nor is this counter-precedential posture limited to originalists or textualists. Learned Hand argues for very limited First Amendment and due process review, and states: "I am well aware that the [Court's] decisions do not so narrowly circumscribe the power of courts to intervene" under these provisions. ${ }^{100}$ Judge Posner, defending a pragmatic and empirically sensitive approach to constitutional decisionmaking in Against Constitutional Theory, works through the VMI and Romer cases as examples of how "the Court does not base its constitutional decisions on fact," ${ }^{\text {101 }}$ which he views as pervasive. Charles Black, in Structure and Relationship, stresses throughout the book the unfortunate fact that constitutional caselaw generally (if not invariably) fails to engage in structure-and-relationship reasoning: "What can be asserted is that our preference for

\footnotetext{
${ }^{95}$ See, e.g., Ackerman at 48 (noting that the "process of interbranch struggle and popular mobilization made the elections of 1866 and 1936 decisive events in constitutional history").

${ }^{96}$ Prior sections discuss all the CI-participants who I read as relying on precedent, on Framers' intent, and on culture/tradition.

${ }^{97}$ Of course, a CI-participant who discusses the inconsistency of her favored interpretive method with precedent might take the view that this inconsistency is prima facie grounds against the method, but that other considerations on balance favor the method. However, one would think that a CI-participant who believes that precedent is indeed prima facie grounds for a method would try to explain away the troubling (by her lights) inconsistency between her favored method and precedent by explaining that precedent is merely prima facie grounds. None of the CI-participants I am about to cite say that - which suggests that they don't believe precedent supports the legal status of a method at all.

${ }^{98}$ Hugo Black at 23-63.

${ }^{99}$ Bork at 101.

${ }^{100}$ Hand at 67.

${ }^{101}$ Posner at 12.
} 
the particular-text style has been a decided one, leading ... to the failure to develop a fullbodied case-law of inference from constitutional structure and relation ...."102 Herbert Wechsler, in Neutral Principles, takes aim at much caselaw -- most famously, Brown v. Board of Education - for failing to rest on neutral principles. ${ }^{103}$

There are also examples, albeit fewer, of authors explicitly disclaiming reliance on Framers' intent or culture/tradition. Keith Whittington quite clearly abjures the relevance of Framers' intent at the level of choosing an interpretive method: "Bootstrapping ourselves into originalism by turning to the founders to authorize such a methodology has been justly criticized."104 Alexander Bickel also disparages originalism, both as an interpretive method and as a higher-level tool for choosing among methods. ${ }^{105}$

As for culture/tradition: it is quite plausible to read Charles Black as claiming that not only judges, but the broader legal tradition, generally fails to engage in structure-andrelationship reasoning. At several points, Black uses the term "legal culture" -presumably meaning some set of practices broader than judges'. "[T]he method of inference from structures, status, and relationship is relatively little attended to in our legal culture."106 Herbert Wechsler's attack on the Supreme Court for being unprincipled is clearly targeted against nonjudicial actors as well. He says explicitly, "this type of ad hoc evaluation is, at it has always been, the deepest problem of our constitutionalism, not only with respect to judgments of the courts but also in the wider realm in which conflicting constitutional positions have played a part in our politics," and proceeds to provide examples of unprincipled stances by officials and citizens. ${ }^{107}$

\section{RoR semantics and CI-discourse}

RoR semantics is a framework for legal statements. Some CI-participants may be making non-legal arguments for interpretive methods. A mismatch between RoR semantics and their arguments is hardly noteworthy.

However, many CI-participants claim that some interpretive method is legally favored. A mismatch between RoR semantics, and legal arguments for interpretive methods, is noteworthy, and will be the focus of my discussion here.

In particular, I will claim that RoR semantics (1) does not, in general, accurately describe the legal statements that CI-participants are making; and (2) does not even minimally vindicate some of the assertions that are characteristic of CI-discourse.

A key point, for both parts of the analysis, will be that Hart's rule-of-recognition model makes the content of the rule of recognition, the ultimate criterion of legal validity,

\footnotetext{
102 Charles Black at 8.

103 See Wechsler at 20-35.

${ }^{104}$ Whittington at 49. See also id. at 3.

${ }^{105}$ Bickel at 16. See also id. at 98-110.

${ }^{106}$ Charles Black at 93. See also id. at 7-8.

107 Wechsler at 12.
} 
a matter of consensus among current officials. I first discuss this point; then discuss the sense in which interpretive methods, and the relevance of social facts to interpretive methods, is controversial in the U.S.; and then turn to the issues of description and vindication.

\section{The Rule of Recognition as a Consensus Rule}

Hart sees the rule of recognition as a special kind of social rule: namely, a social rule among officials stating ultimate legal validity criteria. In general, according to Hart, a social rule exists in a group only if there is some normative standard that group members generally accept. ${ }^{108}$

In particular, then, the existence of the rule of recognition involves official consensus on some ultimate standard of legal validity. Hart writes: "[W]hat is crucial to [the existence of a legal system] is that there should be a unified or shared official acceptance of the rule of recognition containing the system's criteria of validity." repeatedly characterizes the rule of recognition as being accepted by officials as a “common standard." "110 Hart explains that "unity among officials" is "normally presupposed when internal statements of law are made within the system." discusses the case of South Africa, in which the legislature and the courts disagreed about the legislature's competence, and notes that, had the legislature continued to pursue its views in the teeth of the courts', "the normal conditions of official, and especially judicial, harmony, under which alone it is possible to identify the system's rule of recognition, would have been suspended." ${ }^{112}$

To be sure, Hart does not require the ultimate criterion of legal validity to be a matter of consensus among citizens. But he does require it to be a matter of consensus among officials. As Les Green puts the point, "for Hart, the only consensus necessary for law is a consensus of elites,"113 namely officials.

It is also important to understand that Hart does not make official consensus a necessary condition for the truth of every legal proposition. A derivative legal proposition, which is not itself part of the rule of recognition, can be true by direct or indirect application of the rule of recognition, even though officials aren't in consensus with respect to that proposition. For example, officials might disagree about where the boundary line between two cities lies; but if there is a statute on the books that specifies the boundary, and if the statue is valid by derivation from a rule of recognition which officials commonly accept as an ultimate criterion of validity, and if no official believes that her view of where the boundary lies is part of the ultimate criterion, then the legal

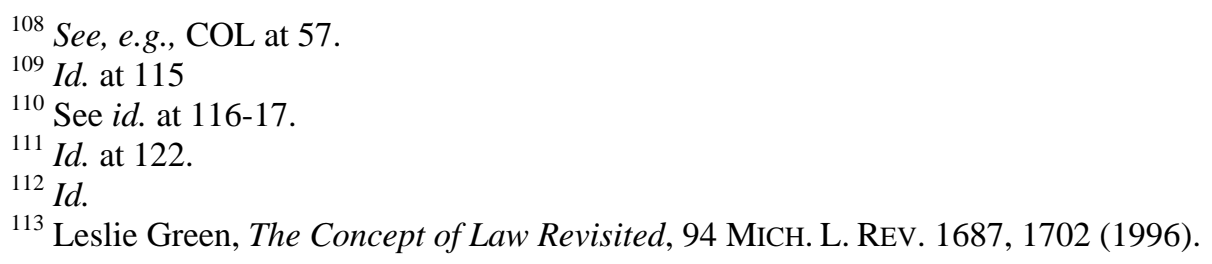


boundary will indeed be a particular line on the map even though many officials deny that this particular line is the boundary. ${ }^{114}$

However, on the Hartian model, a legal proposition cannot be itself part of the ultimate criterion of legal validity unless officials are in consensus with respect to that proposition.

Hart does discuss the possibility of indeterminacy in the rule of recognition. The rule of recognition, like every rule, will have some open texture. ${ }^{115}$

The case of a consensus rule of recognition, which is generally accepted but has some open texture, is different from the case of official controversy about ultimate legal standards. Hart himself seems to view official controversy about the rule of recognition as more pathological than consensus on an open-textured rule. ${ }^{116}$ Still, one might try to domesticate the controversy case, using Hart's notion of indeterminacy, and say the following: where some legal proposition is accepted by some officials as an ultimate legal truth, but rejected by others as a legal truth, then the proposition is indeterminately true $^{117}$ (unless the proposition or its negation is determinately true by derivation from some other proposition that officials generally accept as ultimate). For short, call this the "indeterminacy refinement" to the rule of recognition model.

So, in thinking about the legal status of methods for constitutional interpretation, and the legal relevance of social facts to interpretive methods, under the rule-ofrecognition model, we should be sensitive to the possibility of truth by derivation, and sensitive to the possibility of indeterminacy. Still, even with these nuances in the picture, the rule-of-recognition model says the following: if some present officials deny that an interpretive method is legally favored, ${ }^{118}$ then the method cannot be determinately legally favored as an ultimate legal matter. Similarly, if some present officials deny that certain social facts are legally relevant to the status of interpretive methods, then those facts cannot determinately possess such relevance as an ultimate legal matter.

\section{Constitutional Controversy in the U.S.}

At the outset, it should be stated that current U.S. officials do share a consensus on many legal and, specifically, constitutional matters. For example, they share a consensus (it appears) about the existence of various legal institutions (the President, the Supreme Court, the Congress), and about which natural persons belong to key roles in these institutions. They also share a consensus (it appears) that the text of the 1787 Constitution, as amended, is one key source of higher law. But they lack consensus, I suggest, about two key matters.

\footnotetext{
114 See Coleman, The Practice Of Principle, at 116-17 (discussing possibility of judicial disagreement about the application of a consensus rule of recognition).

115 See COL at 123, 147-54, 251-52.

${ }^{116}$ See id. at 122-23.

117 Neither true nor false.

118 Since to be legally favored, in my terms, is to be at least permissible, to deny that a method is favored is just to take the position that it is impermissible.
} 
First, there are a plurality of interpretive methods that are currently controversial among officials: that are both supported by a substantial number of officials, and opposed by a substantial number of officials. Interpretive methods that are currently controversial among officials include, I suggest, the following: nontextualism, which supplements the text of the Constitution with non-textual sources of constitutional law; textualism, which views the text of the Constitution as the exclusive source of constitutional law; originalism, which looks to original meanings or intentions as the sole basis for interpreting that text; non-originalism, in all its variants, which uses some approach other than looking to original meaning or intentions to interpret the text or other sources (for example, representation-reinforcement, or enforcing moral rights, or implementing judicial doctrine as it has developed over time).

The interpretive methods which are controversial among officials include, in particular, all the methods defended by CI-participants in my sample. How do I know that? To begin, each CI-participant in my sample defends a method that is controversial within the sample itself, and more generally among constitutional scholars. Why mount a lengthy defense of some interpretive method (as participants in my sample do) if the method is universally accepted? One doesn't observe long books or articles arguing that the 1787 text is one source of Constitutional law.

To be sure, it is possible for certain matters to be controverted by legal scholars but not officials generally; and I haven't attempted to directly investigate official beliefs about constitutional interpretation. However, the sample includes jurists as well as scholars, and is plausibly representative of CI-discourse by elites (including prominent officials and judges), not just elite scholars.

Further, Supreme Court constitutional decisions have long been a heated topic of general public debate in the United States. ${ }^{119}$ This public debate has often involved general questions about the appropriate role of courts in constitutional decision making, with many citizens and officials favoring a more expansive role, and many others a more limited role. It is therefore, I believe, quite implausible to think that current officials are in consensus concerning whether the text of the Constitution is the sole source of higher law, and concerning whether the text should be read using an originalist methodology or, alternatively, some particular variant of non-originalism.

Second, the relevance of the social facts of precedent, Framers' intent, and culture/tradition to the legal status of interpretive methods is controversial within my sample. As we have seen, there are some CI-participants who rely on precedent to defend an interpretive method, but others who argue for an interpretive method in the teeth of precedent; and the same is true for Framers' intent and culture/tradition. More generally, the legal relevance of each of these types of social facts is controversial within

\footnotetext{
${ }^{119}$ See, e.g., Adler, Popular Constitutionalism, at 753-65 (describing controversial controversies among officials and citizens).
} 
constitutional scholarship. ${ }^{120}$ And it seems very plausible, then, that their relevance is controversial among current officials: that some but not all officials believe that an interpretive method is bolstered by its grounding in precedent, in Framers' intent, and in culture/tradition.

\section{Does RoR Semantics Accurately Describe CI-Discourse?}

RoR semantics, as I have reconstructed it in Part II, models a legal statement as consisting in a specified package of assertions or presuppositions. To ask whether RoR semantics accurately describes CI-discourse is to ask whether CI-participants are actually making these specified assertions or presuppositions when they are defending interpretive methods as legally favored.

Of course, this may be a matter of degree. RoR semantics might accurately describe none, few, some, many, or all instances of CI-discourse.

My sample suggests that RoR semantics accurately describes few, if any, instances of CI-discourse. The key problem is this: A CI-participant who defends an interpretive method as legally favored, consistently with RoR semantics, must be asserting or presupposing that the interpretive method is contained in, or derivable from, some ultimate criterion of legal validity which is generally accepted by present officials. But CI-participants generally do not seem to be saying this.

To begin, let me note that CI-participants never assert the existence of a present official practice supporting some interpretive method. I cannot find a single instance in my sample where a participant does so. Some CI-participants do explicitly assert the existence of practices that include present official practice, namely by making culture/ tradition arguments: Such arguments cite either present citizen practices, or past-andpresent citizen practices, both of which include official practices (since officials are citizens). However, culture/tradition arguments are, themselves, hardly a universal feature of CI-discourse. Many CI-participants in my sample do not make such arguments.

The obvious response by Hartians, at this juncture, is to suggest that participants in CI-discourse are presupposing rather than asserting some present official practice. Hart is crystal clear that the present fact of official acceptance of the rule of recognition may merely be presupposed, rather than asserted, by legal statements.

But there is a further difficulty, namely that a substantial number of CIparticipants explicitly assert social facts other than present official practice, in particular

\footnotetext{
${ }^{120}$ To be sure, virtually no scholars have considered the relevance of these sorts of social facts as secondorder criteria for choosing interpretive methods. But numerous scholars challenge courts' reliance on precedent, Framers' intent, or culture/tradition as first-order criteria for deciding constitutional cases. Presumably some nontrivial fraction of these scholars would dispute their relevance as second-order criteria. For scholarly challenges to the legal relevance of precedent in constitutional decisionmaking, see Fallon [this volume], at _ (citing sources). For challenges to the relevance of tradition, see Challenges to the relevance of Framers' intent are, of course, numerous. See, e.g., [CITE] [CITE].
} 
precedent, Framers' intent, or culture/tradition, in supporting the legal status of an interpretive method. How are these explicit assertions consistent with RoR semantics?

The dilemma arises, here, because of the foundationalist character of RoR semantics. Consistent with that framework, a social fact can only be asserted in legal argument in two ways: (1) the speaker is asserting the social fact of present official acceptance of the ultimate criterion of legal validity; or (2) the speaker is asserting a social fact which she believes to be legally relevant, directly or indirectly, by application of the ultimate criterion of legal validity. ${ }^{121}$

References to precedent, Framers' intent, and culture/tradition in CI-discourse do not fit under the first prong. So -- if RoR semantics is to describe CI-discourse -- these assertions must somehow be made to fit under the second.

In some instances, it is unproblematic to think of social facts figuring in legal argument by application (direct or indirect) of an ultimate criterion of legal validity. Here's an example. Imagine a society in which there is a written constitution, and present officials accept that the constitution should be interpreted using a Framers' intent method. A judge in this society, consistent with RoR semantics, could decide a constitutional case by (1) presupposing the present official practice; (2) referencing some provision in the written constitution; and (3) explicitly asserting what the Framers intended by that provision.

But a key feature of CI-discourse, one I have tried to stress, is that the social facts of precedent, Framers' intent, and culture/tradition come into play in this body of legal statements at the level of choosing an interpretive method, not at the level of deciding particular cases. The best available strategy for describing this phenomenon, consistent with RoR semantics, is to imagine an ultimate criterion of legal validity that includes certain social facts (precedent, Framers' intent, culture/tradition, or some combination thereof) as the triggering condition for the legal validity of a candidate interpretive method. ${ }^{122}$ That is to say, the ultimate criterion of legal validity has something like the form: "Judges should decide constitutional cases using method M1 if M1 is best supported by SF; judges should decide constitutional cases using method M2 if M2 is

\footnotetext{
${ }^{121}$ Strictly, there is a third possibility, namely that a legal statement is asserting the fact of general efficacy, i.e., the fact of general citizen compliance with legally valid conduct rules; but I will ignore that possibility, since clearly CI-participants are not referring to Framers' intent, precedent, or culture/tradition to show that U.S. law is generally complied with by citizens.

${ }^{122}$ A different strategy is to argue that there is a rule of recognition $\mathrm{R}+$, which does not merely make some particular social facts the triggering condition for interpretive methods. Instead, the relevance of different social facts is itself conditional on further facts. R+ has the structure: "Under conditions C1, judges should decide constitutional cases using whichever method is best supported by SF; under conditions C2 judges should decide constitutional cases using whichever method is best supported by $\mathrm{SF}^{*} ;$....; under conditions $\mathrm{C}+$, social facts are irrelevant to the choice of interpretive methods and judges should use method M1; under conditions $\mathrm{C}++$, social facts are irrelevant to the choice of interpretive methods and judges should use method M2 ....” However, I see no evidence that R+ describes the views of any actual U.S. officials, let alone the totality, and so will not pursue the implausible strategy of seeing CI-participants as presupposing official consensus on $\mathrm{R}+$.
} 
best supported by SF; judges should decide constitutional cases using method M3 if M3 is best supported by SF; ...," where SF is some stipulated social fact or combination of social facts.

Indeed, Kent Greenawalt, in his illuminating attempt to formulate a rule of recognition for the U.S., concludes that the best candidate for our rule of recognition is a rule with this sort of triggering-condition structure: specifically, one that makes Supreme Court precedent the triggering condition for the legal validity of an interpretive method. “[T]he ultimate rule of recognition," he writes, "is approximately this":

(1) Whatever is in the federal Constitution ... is law;

(2) On matters not clear from the text, the prevailing standards of interpretation used by the Supreme Court determine what the Constitution means ..... ${ }^{123}$

Does this triggering-condition strategy work? The key difficulty, here, is that current U.S. officials are not in consensus with respect to the legal relevance of the sorts of social facts cited in CI-discourse. Current U.S. officials do not agree that precedent, Framers' intent, culture/tradition, or some combination thereof, are the triggering condition for the legal validity of an interpretive method. ${ }^{124}$

Now, one could try to make CI-discourse consistent with RoR semantics by offering an error theory of that discourse with respect to the truth about present official practice. One could say this: CI-participants do presuppose the fact of present official acceptance of precedent, Framers' intent, culture/tradition, or some combination, as the triggering condition for interpretive methods. So CI-statements do fit the template of RoR semantics. It's just that their presupposition about present official practice is incorrect.

But the absence of official consensus about which (if any) social facts are the triggering condition for the legal validity of interpretive methods is surely evident to CIparticipants, at least the sophisticated participants in my sample. For each category of social fact (precedent, Framers' intent, culture/tradition), there are some who assert it but others who explicitly disclaim its relevance. Are we to assume that this lack of consensus, within CI-discourse, is somehow opaque to CI-participants -- that we are aware of it, examining their discourse, but they are not? A more plausible description of the beliefs of CI-participants is that they do not believe themselves to be in consensus about the relevance of social facts to the legal validity of interpretive methods, and therefore do not believe officials to be in consensus either. If CI-participants do not believe officials to be in consensus about the status of precedent, Framers' intent, or culture/tradition as the triggering condition for the legal validity of interpretive methods,

\footnotetext{
${ }^{123}$ Kent Greenawalt [this volume], at _ . Ken Himma gives Supreme Court decisions a yet more substantial role in functioning as a component of the rule of recognition. Himma [this volume], at

${ }^{124}$ In particular, Greenawalt's and Himma's proposals are problematic as attempts to formulate a rule of recognition for the United States because it is controversial, among U.S. officials and citizens, whether the Supreme Court has any role in shaping ultimate validity criteria above and beyond its role of deciding particular cases. See Adler, Popular Constitutionalism, at 724, 760-61, 784 (discussing challenges to Cooper v. Aaron); Fallon [this volume], at _ (discussing challenges to constitutional role of precedent).
} 
then these participants cannot be presupposing that consensus when they rely on precedent, Framers’ intent, or culture/tradition to justify an interpretive method.

Note that what I earlier called the "indeterminacy refinement" to the rule-ofrecognition model doesn't help the Hartian, here. If some officials believe that certain social facts are the triggering condition for interpretive methods, but other officials deny that these social facts bolster the status of interpretive methods, then the relevance of those facts to the methods will, at most, be indeterminate. ${ }^{125}$ CI-participants who are aware of the fact of official controversy, and who are making legal statements consistent with the Hartian model, will not take the position that those facts provide determinate support for some interpretive method. But, in practice, CI-participants who rely on precedent, Framers' intent, or culture/tradition to argue for various interpretive methods do seem to think that these facts provide determinate support for the methods.

\section{Does RoR Semantics Vindicate CI-Discourse?}

Before we turn to the question at hand, several preliminary points are in order.

First, where there are a variety of assertions characteristic of some target discourse, it may be possible to vindicate some but not all of the assertions.

Second, the extent to which we can vindicate a particular assertion characteristic of a target discourse is itself a matter of degree. Imagine that some participants in moral discourse assert that a particular behavior is morally good (assertions which we understand as ascribing the property of moral goodness to the behavior), and that other participants make contradictory moral assertions (which we understand as ascribing the property of moral badness to the behavior). It is impossible, in this case, to vindicate all the assertions: a behavior can't be both morally good and morally bad. However, we might aim to vindicate some of the assertions: to show that there really are properties of moral goodness and badness, and that the behavior possesses one or the other property. By contrast, a moral "error theorist" such as Mackie will claim that the discourse cannot be vindicated at all. ${ }^{126}$ She will claim that that there are no moral properties, and that the moral speakers are universally mistaken in presupposing the existence of such properties and ascribing them to behaviors.

Third, we might ask about Hart's own aims in developing his rule-of-recognition account. To what extent did Hart himself hope to vindicate the claims that participants in a legal system typically make?

Pretty clearly, Hart did not aim to show that law creates genuine reasons, moral or other. He writes in the Postscript:

\footnotetext{
${ }^{125}$ More precisely, it will be indeterminate unless determinately relevant by application of a rule such as $\mathrm{R}+$. See supra note _ . But there is no official consensus on a rule such as $\mathrm{R}^{+}$, and CI-participants surely don't believe otherwise.

${ }^{126}$ See Part I.
} 
My account is descriptive in that it is morally neutral and has no justificatory aims: it does not seek to justify or commend on moral or other grounds the forms and structures which appear in my general account of law, though a clear understanding of these is, I think, an important preliminary to any useful moral criticism of law. ${ }^{127}$

However, it would be a mistake to think that Hart did not aim to vindicate legal statements at all. Hart may have been a skeptic about the moral force of law, but he was certainly not a skeptic about the existence of law itself. Hart thought of a legal system as a genuinely distinctive way in which a society might be organized, built upon a special kind of social fact: official acceptance of a rule of recognition. Because this distinctive kind of social organization can arise, legal rules and legal positions can actually exist; and, where they do, an assertion of their existence, and of their grounding in social fact, will be true. Indeed, The Concept of Law argues at length that the rule-of-recognition model, by contrast with Austin's model, is able to vindicate characteristic beliefs and assertions of participants in legal systems, e.g., concerning the persistence and continuity of law, the existence of legal powers as well as duties, the existence of customary law, and limitations on legislative authority.

With these preliminaries tucked away, we can ask: how well does RoR semantics, and more generally Hart's rule-of-recognition model of a legal system, vindicate CIdiscourse?

RoR semantics does not even minimally vindicate CI-participants' characteristic assertion that some interpretive method is legally favored -- because the interpretive methods characteristically defended by CI participants are controversial, as I've discussed. According to the rule-of-recognition model: if some officials deny that an interpretive method is legally favored, the method cannot be legally favored as an ultimate legal matter. The indeterminacy refinement allows that a controversial method might be indeterminately legally favored. But this refinement doesn't do much to vindicate CI-discourse, because CI-participants are asserting that one or another method is determinately favored, not merely indeterminately so.

The RoR framework does allow that an interpretive method, albeit controversial, might be determinately legally favored if the method is derivable by application of the ultimate criterion of legal validity, rather than being part of that criterion. But, as a matter of the actual facts of social practice in the United States, it is very hard to believe that there is a "deep" rule of recognition that is universally agreed upon by present officials, and whose application will yield any of the controversial interpretive methods defended by CI-participants. Try to formulate that rule!

Further, RoR semantics and the rule-of-recognition model fail to even minimally vindicate the reliance by CI-participants on the social facts of precedent, Framers' intent, and culture/tradition to argue for the legal status of interpretive methods. U.S. officials

${ }^{127} \mathrm{COL}$ at 240. 
do not, in fact, accept an ultimate criterion of legal validity that makes certain social facts the triggering condition for the legal status of interpretive methods. ${ }^{128}$ Therefore, given the rule-of-recognition model of a legal system, an assertion or presupposition by a CIparticipant that precedent, Framers' intent, or culture/tradition determinately bolsters the legal status of an interpretive method will be incorrect.

Finally, does RoR semantics vindicate the normative cast of CI-discourse? As just mentioned, Hart's aims, in The Concept of Law, were not normative. Hart conceptualized a certain kind of human activity, law, which involves normative statements and judgments; but The Concept of Law did not aim to characterize the kinds of considerations that constitute genuine normative reasons. It is therefore perfectly consistent with RoR semantics and the rule-of-recognition model to believe that judges have a genuine normative reason (for example, a moral reason) to follow one or another interpretive method. And it is perfectly consistent with RoR semantics to believe that certain social facts strengthen a judge's normative reason to employ some interpretive method. For example, it is perfectly consistent with these frameworks to think that the Framers were epistemic authorities with respect to the normative bona fides of interpretive methods; that precedent has epistemic authority; or that considerations of stability and reliance give judge genuine reasons not to depart from tradition.

So adopting RoR semantics and the rule-of-recognition model does not mean adopting an error theory with respect to CI-participants' characteristic assertion that judges have a genuine normative reason, perhaps bolstered by social facts, to employ some interpretive method. But adopting RoR semantics and the rule-of-recognition model does have the upshot (1) that CI-participants are systematically mistaken in thinking that one or another controversial interpretive method is determinately legally favored; and (2) that CI-participants are systematically mistaken in thinking that the nexus between an interpretive method and social facts such as precedent, Framers' intent, or culture/tradition, determinately buttresses its legal status. In short, there are real costs, in adopting RoR semantics and the rule-of-recognition model, in our ability to vindicate CI-discourse.

\section{Can We Develop a "Better” Model than RoR semantics?}

Can we develop a "better" model of CI-discourse than RoR semantics? I have stressed that the "goodness" of a scholarly model, such as RoR semantics and, more generally, models of law and legal systems, depends on the scholar's aims and interests. A model may describe very well what legal participants are doing and saying, but explain little of it. It may describe only some of what they say and do, but explain quite well what it does describe. A model may describe and explain beautifully, but provide an "error theory” of legal practice, which sees participants as systematically mistaken in various important ways.

\footnotetext{
${ }^{128}$ Nor do they accept a more recondite rule such as $\mathrm{R}+$, see supra note __.
} 
If our aim is simply to describe CI-discourse, then clearly we can do better than RoR semantics. Consider the following framework for legal statements: A legal statement (1) asserts the existence of some legal position; (2) asserts or presupposes that the position has normative force; and (3) may, but need not, assert or presuppose that some social fact is part of the grounds of (1) or (2). This framework perfectly describes each and every case in which a CI-participant argues that some interpretive method is legally favored. Because the framework is so permissive, in its stipulated components of legal discourse, it has no trouble matching what CI-participants are saying. Of course, the framework explains nothing (why do CI-participants rely on certain facts, or characterize certain methods as legal?); nor does it help to vindicate anything they say.

What if our aim is to both describe and vindicate CI-discourse? Here, improving on RoR semantics becomes more difficult. The fact that RoR semantics fails to vindicate CI-discourse may just be one upshot of the fact that CI-discourse is relatively intractable to vindication.

I emphasize "may,” because it is impossible to reach clear conclusions without systematically analyzing CI-discourse through the lens of a variety of plausible jurisprudential theories. Of course, "plausible" is itself relative to our aims. So I guess the real test for whether the failure of RoR semantics to describe and vindicate CIdiscourse is the "fault" of RoR semantics, or of CI-discourse, would be something like this: Take accounts of law that do pretty well in describing and vindicating legal discourse in various domains. In that sense, they are "plausible." Then apply them to CIdiscourse in particular. If they all fail to vindicate characteristic assertions by CIparticipants, then the conclusion should be that CI-participants are, indeed, systematically mistaken in those assertions.

I, of course, lack the space to undertake this analytic exercise here. However, a very preliminary stab at examining CI-discourse through non-Hartian theories suggests no easy solution to the puzzle of how interpretive methods can be genuinely legally favored in the teeth of official disagreement, and how certain social facts can bolster the legal status of some interpretive method in the teeth of official disagreement about the relevance of those facts.

Some post-Hartian positivists reject Hart's view that the rule of recognition is a social rule in the sense he describes, and instead argue that ultimate criteria of legal validity emerge from a shared cooperative activity ("SCA") among officials. ${ }^{129}$ On this view, officials are committed to working together to maintaining a unified system of rules. Officials may not have the same conception of what that unified system should be; but they all intend to develop such a system and, in particular, to "mesh" their competing conceptions of legal validity in a cooperative manner.

\footnotetext{
${ }^{129}$ I discuss the SCA view in Adler, Popular Constitutionalism, at 750-65; and Matthew D. Adler, Constitutional Fidelity, the Rule of Recognition, and the Communitarian Turn in Contemporary Positivism, 75 FoRDHAM L. REV. 1671, 1682-87 (2006). Scott Shapiro, who was central to the development of this view, has recently adopted a different view. See Shapiro [this volume].
} 
Whatever the virtues of the SCA account, it does not actually seem to explain how a controversial proposition can be part of the ultimate criterion of legal validity. Some officials believe that $\mathrm{P}$ is an ultimate legal proposition; others believe that $\mathrm{Q}$, which contradicts $\mathrm{P}$, is an ultimate legal proposition. The officials are cooperative, and committed to working through their disagreement about $\mathrm{P}$ versus $\mathrm{Q}$-- but until they actually do that, and come to consensus one way or the other, how can either P or Q really be determinately true?

Further, as I have argued at length elsewhere, the SCA account does a questionable job of describing actual constitutional practice in the U.S., because it is doubtful that officials are as cooperative as the model requires. Officials holding competing constitutional conceptions may well lack an intention to mesh their views with each other. Thus, to the extent that an SCA-based semantics stipulates that legal statements assert or presuppose that officials are cooperative, that semantic framework will fail to describe CI-discourse very well. ${ }^{130}$

Both Hart's view and the SCA view posit a single, canonical, "recognitional community" of officials, whose practices give rise to law. I have previously suggested a different view: that the truth of legal statements might be relativized to various official or citizen groups. ${ }^{131}$ This "group-relative” account does not make general official or citizen consensus a necessary condition for the determinate truth of ultimate legal propositions. If a group accepts some ultimate criterion of legal validity (and if norms validated by this criterion are sufficiently effective in shaping behavior, within or outside the group), then the components of that criterion will be ultimate, determinate, legal truths, relative to the group -- whether or not these propositions are accepted by non-members. In particular, if a group accepts an interpretive method, or the proposition that certain social facts are relevant to the legal status of an interpretive method, then CI-discourse that defends the method, or adduces such facts, relative to this group, will be vindicated -- even if the interpretive method, or the relevance of the facts, is controversial outside the group.

However, there is a very important way in which the group-relative account fails to vindicate CI-discourse. Thinking of propositions of constitutional law as being true or false in a relative rather than absolute sense is deeply revisionary. To be sure, we all recognize that constitutional requirements may change over time, and that the corpus of constitutional law may have areas of fuzziness and indeterminacy, but the notion that there are a very large number of distinct bodies of constitutional law in the U.S. at a given period of time (corresponding to each separate group) is deeply unfamiliar. CIparticipants, in particular, do not assert that controversial interpretive methods are legally favored, relative to one or another group; but just that they are legally favored, period. There is a sense in which, even for the group-relative framework, a noncontroversial proposition can be true in an absolute sense (namely, because it will be true relative to all groups). But the framework sees as mistaken the characteristic attempt of CI-participants to assert that some interpretive method, or the relevance of some social fact, is part of the

${ }^{130}$ Assuming CI-participants understand that officials are not very cooperative.
${ }^{131}$ Adler, Popular Constitutionalism. 
single system of constitutional law that binds all of us, even though some of us fail to accept the method or the relevance of the fact.

Finally, what about Dworkin's conception of law, "law as integrity”? One of Dworkin's chief criticisms of Hart has long been that the rule-of-recognition models ties law too tightly to consensus. ${ }^{132}$ Legal propositions can be both controversial and true, Dworkin emphasizes -- and "law as integrity" explains how. A legal proposition is true just in case it is validated by the constructive interpretation of the preinterpreted legal data that is best, all things considered, in both fitting the data and in being morally justified. Current community (specifically, citizen) consensus determines what the preinterpreted data is, but not what the best constructive interpretation is. ${ }^{133}$ Note further that, for Dworkin, legal argument is not straight moral argument, but rather a mixture of certain social facts (the preinterpreted data) and moral considerations.

In both these senses, law-and-integrity seems to be a promising framework to describe CI-discourse. But are CI-participants actually engaged in anything like constructive interpretation? Some are -- for example, Fallon, Strauss, Ely, Ackerman, and Perry, all of whom ground interpretive methods in culture/tradition facts in a manner not too distant from constructive interpretation. It is less clear whether the pervasive reliance on Framers' intent to buttress interpretive methods is consistent with the "law as integrity” model. Since current citizens do not agree that Framers' intentions are legally relevant, it is hard to see why their intentions have much weight in determining which interpretive method to adopt, under the law-as-integrity model. ${ }^{134}$ Dworkin himself has been a vigorous critic of the reliance on Framers' intent in constitutional argument. ${ }^{135}$

A deeper difficulty with relying on Dworkin's law-as-integrity model to describe and vindicate CI-discourse is that the model rests on a problematic moral view. Law's Empire, a work of normative theory, revolves around the claim that there exists an independent moral value, "integrity," which is distinct from the various moral considerations that a substantial number of moral theorists have long argued for -equality, overall welfare, fairness, rights not be harmed and other deontological rights, democracy, or due process. Dworkin's defense of this novel value is based on our intuitions that the state should speak with one voice, and on a putative link between integrity and associative obligation. In a political community where members accept the value of integrity, by identifying the content of law through constructive interpretation, the conditions for associative obligation arise and law will genuinely have prima face moral authority. Those conditions are that members believe they possess -- or behave as if they believe they possess -- special responsibilities to each other flowing from an equal concern for each others' well-being.

\footnotetext{
132 See, e.g., DWORKIN, LAW's EMPIRE; RONALD DWORKIN, TAKING RIGHTS SERIOUSLY (1977)

133 See Adler, Popular Constitutionalism, at 737-45 (defending this reading of Dworkin).

${ }^{134}$ Perhaps Framers might be taken as epistemic authorities with respect to various moral considerations. But surely Framers are not epistemic authorities with respect to constructive interpretation, because constructive interpretation synthesizes morality with present practices, and the Framers, who died long ago, know nothing of present practices.

135 See, e.g., DWORKIN, LAW’s EMPIRE, at 355-99.
} 
Denise Réaume has provided a devastating critique of Dworkin's argument for integrity. ${ }^{136}$ Among other things, Réaume points out that Dworkin's conditions for associative obligation amount to a kind of moral bootstrapping. The conditions mean that members of a community who sincerely believe and act upon a flawed egalitarian ideology owe genuine prima facie moral duties to each other just by virtue of this social fact. Dworkin limits the counterintuitive implications of this claim by stipulating that the community must not be too unjust -- but, even so, the claim is startling and troubling. Consider a theocracy which provides for its citizens' material needs, and affords them some rights of political participation, but requires them to engage in religious observance in service to a nonexistent deity, to whom the regime and citizenry genuinely believe all citizens to be equally subject. Do these edicts have genuine moral authority for the citizens? Or consider a society with a system of ethnically-based occupations. Members of different ethnic groups hold each other in equal regard but sincerely believe that different groups are specially suited for different occupations. Laws limit the occupational choices of each group's members. Do the citizens have a prima facie moral obligation to comply with these misguided laws?

In short, although Dworkin's law-as-integrity model, with its methodology of constructive interpretation, does describe CI-discourse somewhat more accurately than RoR semantics, relying on that model to vindicate CI-discourse is problematic -- because doing so means accepting Dworkin's novel and (I believe) implausible claim that integrity is a genuine moral value.

\section{Conclusion}

Constitutional scholars have paid surprisingly little attention to the structure of their own arguments. When scholars and jurists defend some controversial method for interpreting the Constitution, such as originalism, textualism, common law constitutionalism, representation reinforcement, and so forth, they typically seek to show that the method is legally required, permitted, or otherwise favored, and often draw on various kinds of social facts to strengthen the argument. An important puzzle, worth more scholarly attention than it has received, is how to "make sense" of these features of constitutional argument.

This chapter has argued that Hart's rule-of-recognition model of legal statements doesn't resolve the puzzle. That model is neither particularly accurate in describing what proponents of interpretive methods say, nor particularly helpful in vindicating their characteristic assertions and presuppositions. Whether a different model of law can do a better job, in these respects, is an open question.

\footnotetext{
${ }^{136}$ Is Integrity a Virtue? Dworkin's Theory of Legal Obligation, 39 U. TORONTO L. REV. 380 (1989).
} 